\title{
LA CONSTRUCCIÓN \\ DEL CENTRO POLÍTICO EN MÉXICO. \\ UN ACERCAMIENTO \\ A PARTIR DE LA EXTINCIÓN \\ DE LA CONTRIBUCIÓN FEDERAL (1948)
}

\author{
Luis Aboites Aguilar \\ El Colegio de México
}

Al paso que vamos el secretario de Hacienda va a tener que ir con los gobernadores a pedirles apoyo económico, y no como ocurre ahora. ${ }^{1}$

\begin{abstract}
Mu poco ha llamado la atención de los historiadores y 1 en general de los estudiosos de la fiscalidad mexicana contemporánea la extinción de la contribución federal (CF en adelante), una carga que obligaba a los estados y municipios a entregar una parte de sus ingresos fiscales al gobierno federal. Al aprobar la medida, prevista en la ley de ingresos para el año de 1949, el Congreso de la Unión dejó atrás 125 años de vigencia de esa carga fiscal, conocida también como la "cuarta federal". ¿Qué significado tiene tal decisión? ¿Por qué es importante detenerse en ella?
\end{abstract}

Fecha de recepción: 14 de marzo de 2017

Fecha de aceptación: 6 de julio de 2017

${ }^{1}$ Declaración del secretario de Hacienda, José Antonio Meade, La Jornada (viernes 9 jun. 2017), nota de Roberto González Amador sobre el discurso del funcionario en la ceremonia de entrega del premio UNAM-Interacciones sobre finanzas estatales. 
Este trabajo intenta mostrar que la desaparición de la CF es un acontecimiento cargado de pistas que permiten profundizar en la historia política mexicana, en especial en las relaciones entre el centro y las provincias; además, ofrece criterios novedosos para distinguir épocas y tendencias que bien pueden servir para ensayar una visión de largo plazo. Esa perspectiva larga no sólo es útil para el trabajo historiográfico; también puede animar la reflexión de los propios historiadores en torno a la situación de México durante las primeras décadas del siglo xxI.

Al estudiar la extinción de la CF, se busca establecer una conexión entre esa carga fiscal y un fenómeno más amplio, referido a la formación del centro político de la nación, entendido éste simplemente como el gobierno general o federal, con sede en la Ciudad de México, con capacidad para imponer sus decisiones al conjunto de provincias en los ramos fundamentales del quehacer gubernamental, en particular en materia tributaria. Se trata de argumentar que en términos tributarios hay un antes y un después de 1948, y que en el esfuerzo por caracterizar una y otra época aparecen indicios que ilustran bien la complejidad que entrañaba la tarea de construir el centro político de la nación. Se da preferencia al periodo posterior a 1948, en particular a los acontecimientos de 1972-1973, referidos a la negociación que hizo posible la generalización del impuesto federal sobre ingresos mercantiles (ISIM en adelante). Esos acontecimientos se leen de dos maneras: por un lado, como rápido mentís al poderío federal expresado en la extinción de 1948; y por otro, como inicio de una nueva época marcada tanto por el debilitamiento hacendario del gobierno federal, del centro, como por el ascenso de los gobiernos provinciales.

El trabajo consta de cuatro apartados: el primero trata de los antecedentes de la CF, que nació en 1824 con otro nombre (contingente); el segundo detalla el acontecimiento de 1948 a la luz de los cambios de la hacienda pública federal iniciados en la década de 1870; el tercero revisa gruesamente las secuelas 
del arreglo de 1972-1973 en la trayectoria de las participaciones federales, el mecanismo opuesto por antonomasia a la CF; y por último, en las conclusiones, se recapitula en torno a una propuesta de periodización que intenta conectar la extinción de 1948 con la situación de la década de 1820 y con la situación presente (2015-2017). Con ello, se trata de propiciar la reflexión acerca de una perspectiva de largo plazo para hacer una historia política mexicana. $^{2}$

\section{ANTECEDENTES:}

PROVINCIANOS CONTRA EL CENTRO EN 1823-1824 Y SECUELAS

¿Cuál es el origen de la CF y por qué se dice que su extinción es una atractiva vía para hacer una historia política de largo plazo? La CF nació en el contexto del ascenso político de las provincias, fenómeno influido por la creación de las intendencias en 1786 y de las siete diputaciones provinciales surgidas a raíz de la Constitución de Cádiz de 1812, lo mismo que por la guerra de Independencia. En los primeros años de vida independiente, los grupos provincianos temían y se oponían a que el nuevo país se organizara alrededor de un poderoso centro político con sede en la ciudad de México. Recuérdese que en marzo de 1823 el emperador Agustín de Iturbide había caído en virtud del alzamiento de Casa Mata, encabezado por el entonces veinteañero Antonio López de Santa Anna. En un contexto de crisis de las finanzas públicas, provocado entre otras cosas por la extinción del tributo indígena, la crisis de la minería y la desorganización administrativa, el plan respondía a la decisión del emperador de suprimir el Congreso en octubre de 1822, una medida que buscaba acallar las voces opositoras, entre ellas las provincianas. $\mathrm{La}$ rápida caída del imperio iturbidista mostró la inviabilidad de un gobierno central fuerte. Los grupos regionales ganaron terreno e

${ }^{2}$ Agradezco cumplidamente la sabiduría y generosidad de los dictaminadores. 
influencia, en particular los de Jalisco y Zacatecas. Así se explica el surgimiento de la república federal en 1824. ${ }^{3}$

La nueva criatura política cumplía con las exigencias de los rebeldes triunfantes de 1823, a saber, un centro político de bajo perfil, rasgo que se aprecia bien en el modo en que se arregló la hacienda pública y detrás de ella la relación centro-provincias. En la ley de clasificación de las rentas, del 4 de agosto de 1824, el Congreso distribuyó los ramos tributarios entre los gobiernos provinciales y el federal. Algunos de los principales (alcabalas, derechos de oro y plata, contribuciones directas, venta de cigarros) quedaron en manos de los estados. El gobierno federal obtuvo, entre las rentas más importantes, las del comercio exterior (la aduana de Veracruz en primerísimo lugar), el papel sellado, el cobro de las alcabalas en el Distrito Federal y demás territorios federales, la explotación de la sal, el correo y la renta del tabaco en rama. El resultado fue que el poder federal quedó maniatado por los estados, limitando su quehacer a los territorios federales. Por ello, no tenía trato tributario con la población en su conjunto. Como afirma un autor, se trataba de un Estado $\sin$ territorio, "sin una verdadera soberanía financiera". ${ }^{4}$

La distribución de rentas de 1824 tuvo consecuencias duraderas. Minar de ese modo la hacienda federal obligó a los estados a proveerla de recursos. Y tal es precisamente el origen de la CF, en un principio llamada contingente. Ésta nació imponiendo una carga a los estados, cuyo monto se estimó por el número de habitantes, por las características económicas regionales y por el monto de los pagos del diezmo eclesiástico realizados en cada una de las provincias. Los municipios no tenían obligación. Los estados más poblados y prósperos, ubicados en el centro y occidente del país (México, Puebla y Jalisco), quedaron comprometidos con las mayores aportaciones; a los tres les correspondería

3 VÁzquez, "El federalismo”, pp. 17-27.

${ }^{4}$ Carmagnani, “Finanzas”, pp. 139 y 141; Jáuregui, “Los orígenes”, pp. 81-83. 
pagar más de la mitad (casi 53\%) de los 3.1 millones que arrojaba la suma total anual del contingente. A su vez, esta cantidad representaba cerca de $30 \%$ del presupuesto federal, casi como el petróleo a fines del siglo xx. ${ }^{5}$

El diseño hacendario de 1824 enfrentó graves dificultades, en buena medida por los efectos económicos de la guerra de la década anterior, por el desmantelamiento del sistema hacendario colonial y por la beligerancia de los grupos provincianos que no dejaron de oponerse al gobierno con sede en la Ciudad de México. La insuficiencia de ingresos y los excesivos gastos (militares) llevaron al gobierno federal a contratar deuda extranjera y poco después a recurrir a agiotistas, medidas que enrarecieron el ambiente político. Como ingrediente de esa complicada situación, los gobiernos estatales, luego de un inicio prometedor, dejaron de pagar el contingente, dando un nuevo revés a la hacienda federal. Para 1831 los adeudos de los estados ascendían a $23 \%$ del total, proporción que aumentó en las siguientes décadas. ${ }^{6}$ Pero aun así, el contingente era clave en la organización política de la naciente nación. Al respecto, Castañeda Zavala afirma:

La capacidad de los gobiernos estatales para negociar continuamente sus obligaciones con la Federación, fue uno de los varios elementos que contribuyeron a mantener la unidad nacional, aunque en el mediano plazo no llegó a ser suficiente para lograr estabilidad y paz social. De igual forma, las tensiones políticas entre los poderes regionales, y de éstos con el gobierno nacional, reflejaron la deficiente integración de la economía nacional y con ello las propias debilidades del contingente. El costo más alto de este proceso fue la separación de Texas y la "venta" a Estados Unidos de América de gran parte del territorio.?

${ }^{5}$ Castañeda Zavala, “El contingente”, pp. 138-141.

${ }^{6}$ Castañeda Zavala, "El contingente", pp. 144-145.

7 Castañeda Zavala, "El contingente", p. 180. 
Las dificultades hacendarias de las primeras décadas de la vida nacional han suscitado diversas reacciones en distintos momentos. Una de ellas es la crítica al federalismo y a la crecida fortaleza de los gobiernos provinciales, rasgo que se asocia con lo que parece ser su corolario: un centro débil. Lucas Alamán y Lázaro Cárdenas parecen emparentados en su caracterización del problema fiscal y, más allá, de la cuestión de las relaciones entre el centro y las provincias. El primero culpaba al federalismo del estado de cosas: las "autoridades generales" carecían de "medios para hacerse obedecer [...] habiendo las locales usurpado un poder absoluto; de donde resulta que con Estados libres, soberanos e independientes no puede haber hacienda, ni ejército, y, en suma, ni nación”. Por su parte, el presidente Cárdenas afirmaba en 1937 que "en los días siguientes a la desaparición del Imperio de Iturbide el problema que debió plantearse y que ha sido el origen de muchas tragedias de la historia mexicana, fue el de inyectar vitalidad a las descentralizaciones estatales del territorio patrio". ${ }^{8}$ El argumento parece claro: las "descentralizaciones estatales" imposibilitaban la existencia nacional, o al menos la ponían en riesgo y por ello eran vistas como origen de tragedias nacionales. Luego entonces, en el discurso de uno y otro personaje, el centro fuerte aparece como garantía de la existencia nacional, es decir, como lo opuesto a lo que supone un federalismo vigoroso, según el entender de uno y otro.

En 1861 el gobierno del presidente Benito Juárez introdujo cambios en este gravamen que unía fiscalmente al centro con las provincias: por un lado, pasó a llamarse precisamente contribución federal; y por otro, amplió la obligación tributaria a los municipios, que al igual que los gobiernos estatales debían entregar una proporción de sus ingresos al gobierno general. El porcentaje varió en numerosas ocasiones, desde el $25 \%$ juarista

\footnotetext{
${ }^{8}$ Las frases de Lucas Alamán en su Historia de México, v, p. 884, y la de Lázaro Cárdenas, en YÁÑEz Ruiz, El problema, v, p. 229.
} 
hasta el $60 \%$ carrancista; en los últimos años de vida, el porcentaje se mantuvo en 20\%. Durante el periodo 1867-1913, la recaudación anual de la CF pasó de 1.7 a 7.7 millones de pesos, un crecimiento que sin embargo encubría una baja considerable de su peso porcentual en la boyante hacienda federal..$^{9}$ Por desgracia, se ignora el grado de cumplimiento de los estados y municipios en los años posteriores a 1861.

Después de un alza notable en 1918-1921, cuando llegó a aportar casi $21 \%$ del total de los ingresos federales, en los años siguientes la CF vino a menos. ${ }^{10} \mathrm{Su}$ aportación se debilitó y complicó. Si bien entre 1923 y 1948 su monto pasó de 20 a 43 millones de pesos (corrientes), el peso porcentual en el ingreso tributario federal disminuyó de manera notable, de casi $10 \%$ en el primer año a apenas $2 \%$ en el que vendría a ser su último año de existencia. ${ }^{11}$ Varios estudios han mostrado las confusiones que caracterizaron la última etapa de vida del gravamen. Frente a la demanda reiterada de los estados por desaparecerlo, expresada al menos en las convenciones fiscales de 1925 y 1933, la Secretaría de Hacienda había respondido con una política titubeante y contradictoria. Por lo pronto distaba de ser una carga general, pues 13 estados habían logrado obtener algún tipo de exención, mientras que el resto la cubría completa. ${ }^{12} \mathrm{Si}$ el propósito era acabar con la denominada anarquía fiscal, una verdadera obsesión de las autoridades federales de esta época, lo cierto es que el manejo que la propia Secretaría de Hacienda hizo de la CF en estos años acrecentó el desorden. Era un nudo federalista que

\footnotetext{
9 Uhtноғ, "La difícil concurrencia", cuadro 1.

${ }^{10}$ Uhthoff, "La difícil concurrencia", cuadro 2.

11 Aboites Aguilar, Excepciones, cuadros 5 y 7.

12 Gómez TAgle, "La contribución", pp. 20-24; Servín, Las finanzas, pp. 34-40; BetETA, Tres años, p. 127. Las memorias de las convenciones fiscales de 1925, 1933 y 1947, así como de la convención catastral de 1923, son una valiosa fuente de información acerca de las difíciles relaciones entre la Secretaría de Hacienda y los gobiernos estatales. Por desgracia, han sido muy poco aprovechadas. Véase la entrada Secretaría de Hacienda en la bibliografía.
} 
revela todo menos una política definida; en todo caso era expresión de una débil hacienda federal, acosada por las presiones de los gobiernos estatales, un escenario político muy parecido al que describe Castañeda Zavala acerca de la década de 1820. Pero algo queda claro: para 1948 el monto de la CF (43 millones de pesos) era bastante menor a la cantidad que el gobierno federal enviaba a las entidades federativas por medio de las participaciones (119 millones), algo inexistente en la década de $1820 .{ }^{13} \mathrm{La}$ mesa estaba puesta para la extinción de fines de 1948.

\author{
LA EXTINCIÓN DE LA CF \\ Y EL MUY BREVE AUGE FEDERAL
}

Veamos ahora por qué se afirma que la decisión de 1948 es útil para elaborar una visión de largo plazo y también para reflexionar en torno a una nueva periodización relativa a la transición entre los siglos XIx y xx. De entrada, lo más aparente de la iniciativa presidencial de 1948 es que expresa la continuidad del problema surgido en 1824 al crearse la doble soberanía tributaria, es decir, la federal y la de los estados. En esa medida, se trata de un nuevo intento por resolver o por dar un nuevo formato a un problema antiguo. En la iniciativa citada se lee que la extinción de la CF buscaba cambiar la relación entre el gobierno federal y las provincias. En particular, tenía dos objetivos: por un lado, "la delimitación de los campos tributarios de la Federación, de los estados y de los municipios", y por otro, el "robustecimiento de las economías locales bajo la idea concreta de que la coexistencia dentro de nuestro régimen de gobierno de esas tres entidades político-económicas debe fortalecerse mediante una equitativa distribución entre ellas de los rendimientos que

${ }_{13}$ El monto de las participaciones en 1948 en Yáñ̃z Ruız, El problema, V, pp. 318-319. 
la economía pública puede derivar de la privada por medio de los impuestos". ${ }^{14}$

Sin embargo, al mediar el siglo xx, el problema antiguo se ventilaba en condiciones por completo distintas. Tómese en cuenta que en 1824 la CF había nacido con la misión de aportar casi un tercio del presupuesto federal y que en 1948 apenas aportaba 2\% de ese presupuesto. A juicio del presidente Miguel Alemán, tal cambio era una evolución saludable del federalismo mexicano. "La supresión de la Contribución Federal -se lee en la misma iniciativa- representa el sacrificio de un ingreso importante de la Federación en beneficio directo de los fiscos locales". ${ }^{15}$ Sacrificio pequeño, de 2 por ciento.

Quizá por esa pequeñez la extinción de la CF se aprobó sin mayor reparo en el Congreso de la Unión. No hubo voces en contra ni largos discursos de justificación, nutridos con doctas y floridas lecciones de historia patria, como ocurría en el propio Congreso a propósito de otros asuntos (como las reformas al artículo 27 constitucional, de diciembre de 1946). La extinción de la CF formaba parte de la iniciativa de ley de ingresos para 1949, misma que fue entregada a la Cámara de Diputados el 16 de diciembre de 1948. Cinco días después, la comisión de presupuestos y cuenta de la propia instancia legislativa emitió su dictamen favorable. En éste aparecía una breve referencia a la moribunda CF:

La supresión de la CF es el fruto de los gobiernos revolucionarios en su afán de tener una hacienda bien organizada y beneficiar a los fiscos locales. Este gravamen, que se creara en 1827 [sic], desaparecerá ya de nuestra Ley de Ingresos y se acabarán las observaciones y aun las multas que la Federación imponía a los fiscos locales con motivo de su aplicación.

14 Véase el texto introductorio de la ley de ingresos para 1949 en BeteTA, Tres años, pp. 398-404; las frases copiadas, en p. 402.

15 Beteta, Tres años, p. 403. 
Nada que ver con la elocuencia de la iniciativa presidencial. En la misma sesión, la ley de ingresos fue aprobada en lo general (85 votos a favor, 3 en contra) y en lo particular (84 a favor y los mismos 3 en contra). La extinción de la vieja carga fiscal, heredera del contingente de 1824, aparecía en el segundo transitorio de esa ley. ${ }^{16}$ Los senadores, por su parte, fueron un poco más explícitos. En el dictamen favorable a la ley de ingresos ya aprobada por los diputados, la comisión de hacienda expresó lo siguiente:

En el proyecto que estudiamos, es sin duda punto capital el que se refiere a la supresión del gravamen que, con el nombre de Contribución Federal, ha venido cobrándose desde el año de 1861 y que se originó en los primitivos "contingentes" con que los Estados ayudaban al sostenimiento de la Federación. La supresión de este gravamen redundará efectivamente en la mejoría fiscal de las Entidades Federativas y en su economía, sin que, por las nuevas bases del presupuesto federal, éste sufra en forma irreparable la supresión de este concepto. ${ }^{17}$

El Senado no sólo no discutió la ley de ingresos, sino que, al no haber discusión, aprobó el dictamen el mismo día, por unanimidad y por "votación nominal en un solo acto". Otro trámite, después de todo. No deja de llamar la atención el uso del calificativo "primitivos” en referencia a los contingentes. Quizá el optimismo hacendario del gobierno de Miguel Alemán propiciaba dicha caracterización del arreglo tributario de la década de 1820, de los inicios de la vida independiente.

Si el desdén legislativo se explica por la pequeñez del monto de ingresos federales involucrados en la extinción mencionada, hay que explicar tal pequeñez. Ésta obedece a los cambios

${ }^{16}$ Diario de los Debates de la Cámara de Diputados, martes 21 de diciembre de 1948; la ley de ingresos se publicó en el Diario Oficial de la Federación del jueves 30 de diciembre de 1948.

17 Diario de los Debates de la Cámara de Senadores, viernes 24 de diciembre de 1948, p. 6 y 12-13. 
notables ocurridos en las ocho décadas anteriores en las relaciones hacendarias entre el centro y las provincias. Muy poco se parecía al México de la década de 1820, que había hecho necesaria la creación del contingente. Una de las principales diferencias era la transformación de la organización fiscal del país. El gobierno federal había logrado relacionarse con la población y el territorio en su conjunto. Un gobierno federal de carácter nacional, en sentido estricto. En términos hacendarios, la nueva época dio inicio en la década de 1870, con la creación del impuesto del timbre, de la mano del secretario Matías Romero. Un estudioso indica que el propósito de ese gravamen, además de diversificar las fuentes de ingresos de la hacienda federal, era gravar el consumo de mercancías a lo largo y ancho del país, y no solamente en el Distrito Federal y en los territorios federales, como ocurría hasta entonces, siguiendo la ley de 1824 mencionada antes. En esa medida, pretendía lograr que los ciudadanos (y no las provincias) contribuyeran al sostenimiento del gobierno general, una apuesta de claro sello liberal..$^{18} \mathrm{Con}$ ese impuesto indirecto, se sentaban las bases para la expansión (lenta y accidentada pero sostenida) de la soberanía hacendaria federal. A la vuelta de varias décadas, hacia 1910, el resultado era una preponderancia creciente de la hacienda federal sobre las de estados y municipios. Por ello, la década de 1870 resulta fundamental para distinguir las etapas de esta historia.

Lejos de interrumpir o contradecir la expansión federal iniciada en la década de 1870, los gobiernos posrevolucionarios la fortalecieron y diversificaron. Prueba de ello fue la creación en 1925 del impuesto sobre la renta (ISR), también de alcance nacional. Tal expansión federal, que puede rastrearse en otros ámbitos de la administración pública (tierras, aguas, minería, bancos, electricidad, trabajo, educación), se tradujo en el crecimiento más acelerado de los ingresos federales, logrado en ocasiones a

${ }_{18}$ Carmagnani, Estado y mercado, pp. 67-85 y 263-267. 
costa de las finanzas estatales y municipales. En esa medida, el esfuerzo de Alberto Pani, Luis Montes de Oca y Eduardo Suárez, por mencionar algunos de los más destacados secretarios de Hacienda de los primeros años de la época posrevolucionaria, seguía las pautas marcadas 50 años antes por Matías Romero. Fortalecer al centro a toda costa para dejar de depender no sólo de los ingresos aduaneros sino de las aportaciones de los estados, de la provincia, para establecer el trato con la ciudadanía en general. En esa tendencia se ubica la extinción de la CF.

Es importante hacer énfasis en la vigorosa oposición de los grupos económicos y políticos de las provincias a la expansión de la soberanía tributaria federal. Así ocurrió en 1880-1881 a propósito del timbre y en 1924-1925 en relación con el ISR. Tal oposición se alimentaba, como en otros países (Estados Unidos, Argentina), de interpretaciones constitucionales y legales que preferían un gobierno federal pequeño, frágil, acotado. La defensa de la soberanía de los estados, un tema que en México merece una investigación concienzuda, era argumento recurrente. Hay razones para pensar que esa defensa era en realidad una manera de oponerse a formas más efectivas y modernas de tributación. ${ }^{19}$

En 1950, el income tax mexicano aportaba 766 millones de pesos al erario federal, una cifra 18 veces mayor al monto de la CF en su último año de existencia. Medida en pesos y centavos, la diferencia entre un siglo y otro era notable. Con base en la recaudación del IsR, acrecentada gracias al aumento logrado en 1942-1944, el presidente Miguel Alemán podía hacer alarde en 1948 de su fe federalista y de su preocupación por el bienestar provinciano. En los hechos, el cambio hacendario había

19 Sobre Estados Unidos, véase BrownleE, Federal Taxation, pp. 40-46; sobre la disputa constitucional en Argentina, véase Trevisán, Reforma, pp. 13-25; sobre la oposición al impuesto del timbre en México, véase CARMAGNANI, Estado y mercado, pp. 267-274; y sobre la oposición al ISR en 1924-1925, АвOITES Aguilar, Excepciones, pp. 131-143. 
modificado el carácter del federalismo: de referirse en el siglo XIX a una federación compuesta por vigorosos estados libres y soberanos (al menos en el papel constitucional), se definía ahora por un gobierno federal cada vez más poderoso que pretendía someter y limitar la soberanía de los estados. Por lo pronto, los estados no lograron hacerse de una nueva fuente de ingresos de la potencia del ISR.

Ante el cambio hacendario general, conviene detenerse en la situación de las haciendas locales. Desde fines del siglo xIx y hasta 1950, las finanzas de los estados muestran un crecimiento discreto, mientras que los ingresos municipales sufren una caída en picada. La supresión de las alcabalas en 1896 y de los impuestos de capitación en la década de 1910 tuvo un impacto severo en las finanzas estatales, y lo mismo ocurrió a raíz de la supresión de los municipios en el Distrito Federal en 1929. Este último acontecimiento es importante no sólo para explicar la disminución de los ingresos municipales en las cuentas tributarias de la nación; también lo es por el debilitamiento general del municipio en el conjunto nacional. En términos del federalismo fiscal, como se dijo, uno de los principales cambios del paso del siglo XIX al Xx es la preponderancia federal. Si el federalismo se midiera por la equidad en la distribución de las rentas públicas, la llamada dictadura de Porfirio Díaz resultaría ser más federalista, según la definición decimonónica, que el Estado posrevolucionario, al menos hasta 1972 (véase el cuadro 1).

Ahora se entenderá mejor por qué en la iniciativa de extinción de la CF, seguramente redactada por el secretario Ramón Beteta, se insistía en la reanimación de las haciendas locales. Suprimir dicha carga buscaba compensar, al menos en parte, la tendencia declinante que tan bien expresan las cifras del cuadro 1. Pero era claro que librar a los estados y municipios de ese gravamen era insuficiente.

Tan fue insuficiente que la precariedad hacendaria de las provincias trató de ser remediada por una vía opuesta a la CF: las 
participaciones federales. Por así decir, la CF y las participaciones son dos caras de la compleja relación centro-provincias; la primera corresponde al siglo xIx y la segunda al xx. Un breve repaso por la trayectoria de las participaciones puede ser ilustrativo.

\section{Cuadro 1}

DISTRIBUCIÓN PORCENTUAL DE LOS INGRESOS BRUTOS

DEL GOBIERNO FEDERAL, DE LOS ESTADOS Y MUNICIPIOS

Y DEL DISTRITO FEDERAL, 1910-2010

\begin{tabular}{lccccc}
\hline & 1910 & 1949 & 1972 & $1989^{20}$ & 2013 \\
\hline Gobierno federal & 66.5 & 83.0 & 83.1 & 73.5 & 56.6 \\
Estados & 14.9 & 8.7 & 6.5 & 18.3 & 33.1 \\
Municipios & 11.7 & 2.8 & 1.6 & 4.1 & 7.0 \\
Distrito Federal & 6.9 & 5.5 & 8.8 & 4.2 & 3.3 \\
\hline
\end{tabular}

Fuentes: para 1910-1972, АвоITES Aguilar, Excepciones, cuadro 3; para 1989 y 2010, véase nota 20.

Su origen se remonta al siglo XIX, con las sumas que la Secretaría de Hacienda debía entregar a los ayuntamientos de las localidades donde funcionaban las aduanas federales. Pero en el siglo xx las participaciones crecieron, se diversificaron y sobre todo se extendieron al conjunto nacional. El origen del actual sistema de participaciones puede situarse en 1922 y tiene que ver con una fuerte disputa en torno a los impuestos petroleros. Con la nada pequeña ayuda de las compañías petroleras extranjeras, el gobierno federal logró echar atrás la intención del gobierno veracruzano de gravar dicha actividad. En este caso, lo mismo que en el de la minería (1926), electricidad (1933) y otros más, las participaciones sirvieron para doblegar a las entidades fede-

20 Para elaborar las columnas de 1989 y 2010 se tomó el presupuesto federal de Estadísticas 2014, cuadro 16.8; los ingresos totales de estados y del ahora extinto Distrito Federal se obtuvieron de INEGI-BIE, mientras que los ingresos municipales provienen de INEGI-BETA. En los dos últimos casos, se trata de cifras correspondientes al periodo 1989-2015. 
rativas que se resistían a perder su soberanía tributaria. Pero al mismo tiempo que perdían varios ramos tributarios, como los arriba mencionados, los estados no dejaron de oponerse a las pretensiones centralizadoras del gobierno federal. En particular, defendieron a capa y espada el ramo del comercio y la industria, en el que se ubica un anacronismo tributario de gran modernidad: las alcabalas reaparecidas. ${ }^{21}$

No parece casualidad - y eso el lector debe tenerlo muy en cuenta - que un año antes de la extinción de la CF el gobierno federal propuso y logró la aprobación del Congreso de la Unión de un nuevo impuesto a las transacciones comerciales, el IsIM. Y éste, con vigencia a partir de 1948, vino a sustituir a otro impuesto decimonónico, el ya mencionado impuesto del timbre. ${ }^{22}$ El IsIm buscaba uniformar los gravámenes al comercio y a la industria para acabar con la denominada "anarquía fiscal", compuesta por alcabalas y otros desórdenes tributarios locales (tasas y procedimientos diversos así como medidas proteccionistas de los propios estados) que se apreciaban en diversos ramos, como el de la cerveza. En 1949, este ramo logró “federalizarse”, como se decía en las primeras décadas del siglo xx, mediante una reforma al cada vez más hinchado artículo 73 constitucional. Pero no todo podía llevarse a la constitución; el gobierno federal no era tan poderoso. De allí que la Secretaría de Hacienda se viera obligada a firmar convenios de coordinación con todos y cada uno de los estados para hacer efectivo el ISIM. A cambio de participaciones federales, los estados se comprometían a suprimir sus impuestos en el mismo ramo.

Sin embargo, prueba de que la expansión federal distaba de ser un paseo, 14 entidades federativas, entre ellas las más prósperas, se negaron a adherirse al IsıM, manteniendo así sus propios

${ }^{21}$ Sobre la pugna petrolera interna, véase ABortes Aguilar, La disputa; y sobre la reaparición de las alcabalas, del mismo autor, "Alcabalas posporfirianas”. ${ }^{22}$ Molina Armenta, "La coordinación”. 
gravámenes. Bien podría investigarse aún más sobre tal rebeldía u oposición local, ${ }^{23}$ entendiéndola como un episodio más de la sostenida resistencia de los estados a la expansión del gobierno general a lo largo de los siglos xix y xx.

En verdad es lamentable la desatención que nos ha merecido el federalismo del siglo xx, lo que sin duda tiene relación con el predominio de la explicación presidencialista. ¿Para qué estudiar el federalismo en una época en que, por el poder presidencial, virtualmente no existía? Tal suele ser la justificación. Obviamente aquí no se comparte tal postura. La extinción de la CF puede verse como indicio del desmesurado poder presidencial y dar la razón a los presidencialistas. Pero esa es una lectura rápida y parcial, sumamente sesgada. Lo es porque hace incomprensibles acontecimientos tales como la reaparición de las alcabalas o la oposición de las 14 entidades a sumarse al IsIM, según acaba de mencionarse, justo en los años que parecen ser los de mayor auge presidencialista. Pero sobre todo hace ininteligibles los acontecimientos de 1972-1973, que se exponen en seguida.

EL ARREGLO DE 1972-1973 Y EL DECLIVE FEDERAL

A pesar de la pequeña cuantía de los recursos fiscales involucrados, puede proponerse que la extinción de la CF en 1948 marca el inicio de una nueva época en las relaciones centro-provincias en México. ¿Por qué? Porque desde entonces el centro político, a la vez que renunció al derecho otorgado en 1824 de recibir recursos de las provincias, ratificó la obligación de distribuir entre ellas una parte de sus ingresos. Era poner de cabeza el orden tributario decimonónico, deshaciéndose de él. Había razones modernas para proceder de esa manera. Tenían que ver con el propósito de

${ }^{23}$ FARÍAS, “Aspectos”, pp. 96-97. Además de los seis estados de la frontera con Estados Unidos (Baja California, Sonora, Chihuahua, Coahuila, Nuevo León y Tamaulipas), los estados rebeldes eran Nayarit, Jalisco, Chiapas, Veracruz, México, Oaxaca, Zacatecas y Guanajuato. 
acabar con la anarquía que propiciaba el diseño constitucional federal, es decir, la convivencia entre las dos soberanías fiscales; también buscaba imponer la uniformidad tributaria nacional y por ese medio extinguir la odiosa y dañina concurrencia de soberanías tributarias (federal y estatal) que pesaban sobre un mismo ramo económico. En una palabra, era el afán, burgués por antonomasia, de buscar la consolidación del mercado interno, de abrir el camino al libre comercio y someterlo a reglas homogéneas (nacionales). Paradójicamente, ese esfuerzo ocurría en una época de alto proteccionismo económico frente al mercado mundial. Mercado libre hacia adentro, proteccionismo hacia afuera.

Se mostrará sin embargo que el esfuerzo federal por encabezar y organizar la tributación nacional y por imponer su autoridad suprema tuvo un altísimo costo. Así quedó de manifiesto apenas 25 años después de 1948. Si este año expresa el auge hacendario del gobierno federal, 1972-1973 marca su declive. Y si hay algo de razón en la afirmación anterior, el corolario es que el poder federal tuvo mucho menos fuerza y muchos menos años de vida de lo que comúnmente hemos creído.

El peso de las participaciones federales en las haciendas de los estados tuvo un arranque modesto. En 1931 no significaba ni 3\% de los presupuestos de las entidades federativas. Pero debemos averiguar las razones que hicieron posible que en los siguientes años ese porcentaje ascendiera de manera significativa. Para 1955 representaban poco más de $26 \%$ de aquellos presupuestos. ${ }^{24} \mathrm{Y}$ en la década de 1970 , según se verá, las participaciones se acrecentaron aún más, alcanzando porcentajes inimaginables apenas unos años antes. En el cuadro 2 se aprecia el aumento sostenido del monto de las participaciones federales a los estados (las municipales no se consideran aquí) entre 1970 y 2013. Lo que en un principio era un rubro discreto se convirtió

${ }^{24}$ La cifra de 1931 en Gómez TAgLE, “La contribución”, p. 23; y la de 1955 en YÁñez Ruiz, El problema, V, pp. 318-319. 
en las siguientes décadas en un mecanismo fundamental del federalismo fiscal entendido a la usanza del siglo xx, es decir, el centro otorgando fondos a estados y municipios..$^{25}$

¿Qué sucedió en 1972-1973? Como se dijo, este es el segundo episodio de la historia abierta en 1948. En esos años, el arreglo fiscal se modificó sustancialmente gracias a un ajuste en la relación centro-provincias: por un lado, se alcanzó la meta tan deseada por la Secretaría de Hacienda en cuanto a la vigencia plena de la uniformidad tributaria en materia mercantil, con base en un impuesto federal (el ISIM); pero, por otro lado, tal logro sólo pudo alcanzarse minando el poderío federal construido con grandes dificultades desde la década de 1870, según se vio. Una especie de componenda de largo alcance, al menos de 100 años, considerando que en 1870 el secretario Romero propuso el impuesto del timbre, gravamen federal generalizado.

El primer hecho clave es que en 1972-1973 todas las entidades, entre ellas las 14 rebeldes, dejaron atrás sus resquemores y se adhirieron al IsIm. Tal adhesión hizo posible la adopción del IvA pocos años después. Pero la segunda clave es que tal adhesión sólo fue posible gracias al sustancioso aumento de las participaciones a los estados. ${ }^{26}$ Las cifras ilustran: de 2907 millones de pesos del IsIM en 1972, a 12881 en 1976 (4.4 veces), mientras que en otros impuestos federales las participaciones pasaron de 1065 millones en 1970, a 7187 millones en 1976 (6.7 veces); en

${ }^{25}$ Sobre la situación de la hacienda pública de los estados de los años 19001956, véase SERvín, Las finanzas.

${ }^{26}$ Es significativo el párrafo que el secretario de Hacienda dedicó al año siguiente al arreglo de 1972-1973: "La coordinación integral de todas las Entidades Federativas en el impuesto sobre ingresos mercantiles constituye la realización de las aspiraciones, que datan de hace 25 años, de uniformar y armonizar los impuestos internos al comercio y a la industria. Ello bastaría para justificar la importancia de las reformas aprobadas por el H. Congreso el año pasado en este gravamen y pone de manifiesto las negociaciones del Ejecutivo para consumar la celebración de convenios de coordinación con los Estados de la República”, en México, p. 16. 
suma, en estos años las participaciones se quintuplicaron. ${ }^{27} \mathrm{Si}$ se mira el cuadro 2, se verá que los aumentos mencionados no son cosa menor. Tan no lo son que es claro que 1972 resulta ser el último año de apogeo de la hacienda federal. Desde entonces se aprecia una tendencia doble por demás consistente: por un lado, la disminución de la preponderancia federal y, por otro, el fortalecimiento de las haciendas estatales. ¿Cómo puede explicarse, si no es por ese cambio, la siguiente afirmación de un gobernador en 1975?: "Sin aumentar las tasas impositivas, el gobierno del estado ha incrementado sus ingresos fiscales, duplicando el presupuesto en comparación con el de $1973 " .{ }^{28}$

\section{Cuadro 2}

PESO DE LAS PARTICIPACIONES FEDERALES EN LOS INGRESOS TRIBUTARIOS FEDERALES Y EN LOS INGRESOS ESTATALES TOTALES, 1970-2013 (PORCENTAJES, PROMEDIOS MULTIANUALES)

\begin{tabular}{ccc}
\hline & $\begin{array}{c}\text { Con respecto a los ingresos } \\
\text { tributarios federales }\end{array}$ & $\begin{array}{c}\text { Con respecto a los ingresos } \\
\text { estatales }\end{array}$ \\
\hline $1970-1972$ & 2.6 & 11.2 \\
$1973-1979$ & 5.7 & 23.7 \\
$1980-1994$ & 16.5 & 53.0 \\
$1995-1998$ & 31.5 & 78.3 \\
$1999-2013$ & 44.4 & 84.8 \\
\hline
\end{tabular}

FuENTEs: ingreso federal tributario en Estadísticas 2014, cuadros 16.7 y 16.8 ; monto de participaciones: para 1970-1985, INEGI, Finanzas públicas 19701982, cuadro 1.2.1, y Finanzas públicas 1976-1985, p. 22; y su monto y el de las aportaciones federales en el periodo 1989-2013, en INEGI-BIE. No incluye al ahora extinto Distrito Federal.

27 Secretaría de Hacienda, Seis años, p. 7 de la ponencia de Carlos Tello, subsecretario de Ingresos; también Farías, “Aspectos”, pp. 96-97 y anexo 7; Petricioli, "Sobre los efectos"; Авoites Aguilar, Excepciones, pp. 368-369. Gustavo Petricioli, por desgracia ya fallecido, parece haber sido el artífice del arreglo de 1972-1973.

${ }^{28}$ Informe Sonora 1975, p. 23; una afirmación similar se halla en Informe Nuevo León 1974, pp. 70-71. 
Como se aprecia en la gráfica y en el cuadro 2, el peso de las participaciones federales no dejó de aumentar después de 1973, al menos hasta 2003, según se explicará más adelante. Ese ascenso puede dividirse en varias etapas, siguiendo el crecimiento del peso de las participaciones en ambas haciendas. Una primera, que va de 1973 a 1979 y que bien podría denominarse del modelo IsIm, consiste en el aumento al doble del porcentaje de las participaciones tanto en los ingresos tributarios federales como en los ingresos brutos estatales. La segunda etapa se refiere al salto aún más considerable derivado de la adopción del IVA, a partir de 1980, y que dura hasta 1994. Estos 15 años pueden bautizarse como del "modelo IVA". Como se aprecia, representó un mayor esfuerzo para la hacienda federal pues el peso de los envíos a los estados se triplica en cuanto a su porcentaje (pasa de 5.6 a $16 \%$ ), mientras que en las haciendas estatales las participaciones federales "sólo" aumentan de 28 a 53\% en relación con sus ingresos brutos. ${ }^{29}$

El periodo 1980-1994 contiene al menos dos acontecimientos que no deben dejarse de lado. El primero es la severa crisis económica de la "década perdida", como se nombra a la década de 1980, caracterizada por la caída de los precios del petróleo y del crecimiento económico, por una elevada inflación y severos recortes al gasto público, obligados por el peso de la deuda externa. La segunda cuestión se refiere a la caída de los ingresos tributarios de los gobiernos estatales a raíz de la adopción del IVA. Desde la perspectiva de los estados, en efecto, la década de 1970, y en especial la adopción del IvA, trajo consigo la pérdida de la mayor parte de su soberanía tributaria. ${ }^{30}$ Sólo se conservaba el impuesto predial como ramo significativo. Puede pensarse que ante la nueva situación de las finanzas de los estados, los

29 JANNETTI, “La coordinación”, p. 773; y p. 774, sobre las tensiones que creó la disminución de las participaciones federales en años de crisis económica, en particular en 1982 y 1985.

30 JanNETTI, “La coordinación”, p. 771. 
grupos políticos provincianos acrecentaron su exigencia al centro de mayores tajadas presupuestales, para paliar las secuelas de la pérdida de aquella soberanía. Así, la demanda tributaria se sumó a los reclamos contra el autoritarismo presidencial y la antidemocracia que entrañaba el PRI, y de paso contra los presuntos privilegios de que gozaba la Ciudad de México. Todos esos elementos nutrieron la movilización electoral de esos años que abrieron el camino a la transición democrática.

El siguiente periodo se inaugura con la crisis de 1995 y con la continuación de las negociaciones en torno a la transición democrática; termina en 1998. En términos de las relaciones tributarias centro-provincias, la tendencia alcista de los dos indicadores considerados se refuerza. El monto de las participaciones en la hacienda federal casi se duplica (pasa de 16.5 a $31.5 \%$ ) y en las haciendas estatales alcanza un tamaño impensable 15 años antes: se eleva de 53 a 78\%. Por la magnitud de estas alzas, quizá éste sea el periodo decisivo. En el último tramo (1999-2013), la tendencia se sostiene sobre todo en relación con la hacienda federal, pues el peso de las participaciones pasa de 31.5 a más de $44 \%$ de sus ingresos tributarios, mientras que en los estados la tendencia parece estabilizarse; en este caso, el aumento es más modesto, de 78 a 84 por ciento.

En suma, en el nuevo escenario, tan distinto al de inicios de la década de 1970, el dinero federal destinado a los estados involucraba a casi la mitad de los ingresos tributarios y aportaba más de $80 \%$ de los ingresos estatales. Así se explica por lo demás el cambio drástico en la distribución de los ingresos fiscales entre 1972 y 2013, según se indica en el cuadro 1. El año 2003 parece el momento culminante de la tendencia general iniciada en 19721973. En ese año, las participaciones y aportaciones federales en la hacienda federal atraían $44 \%$, pero la contribución federal [sic] a los estados alcanzaba $88 \%$ de los ingresos totales, la cifra máxima a lo largo del periodo 1970-2013. Después de 2003 se registra un leve descenso. Tal vez 2003 mostró el límite: más allá 
de los porcentajes alcanzados en ese año la situación del gobierno federal se volvía insostenible. Tal vez a ese límite se refiere el secretario Meade en el epígrafe.

\section{Gráfica 1}

PESO DE LAS PARTICIPACIONES FEDERALES EN LA HACIENDA

FEDERAL Y EN LAS HACIENDAS ESTATALES, 1970-2013

(PORCENTAJES CON RESPECTO AL INGRESO FEDERAL TRIBUTARIO Y LOS INGRESOS ESTATALES BRUTOS, PROMEDIOS MULTIANUALES)

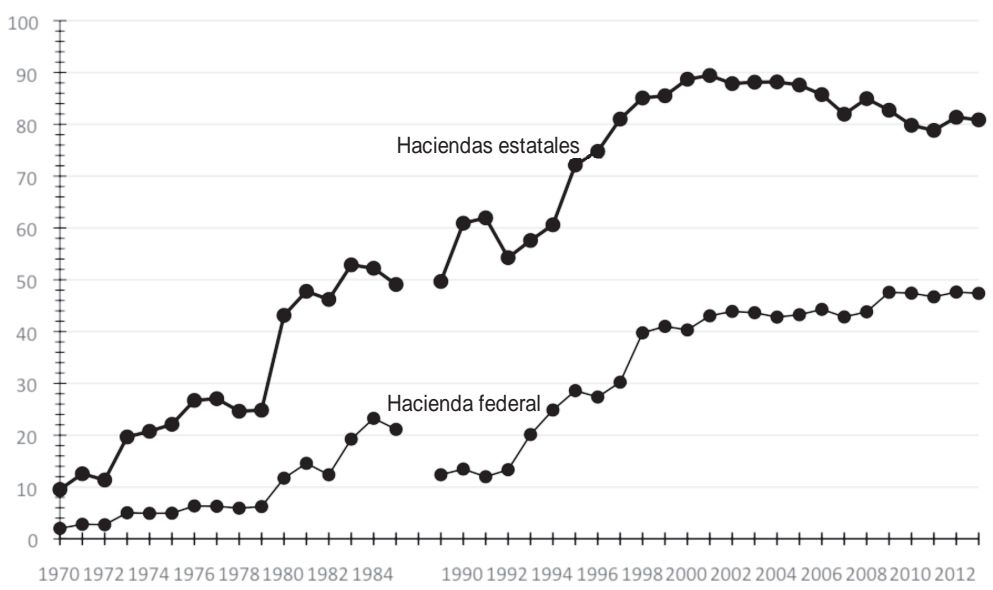

FuENTES: cuadro 2.

¿Qué implicaciones ha tenido semejante cambio en la relación centro-provincias? ¿Qué fuerzas políticas y económicas lo impulsaron? Un párrafo de un experto contemporáneo relaciona el ascenso de la oposición política y la transición democrática de la década de 1990 con el ascenso provinciano y el debilitamiento hacendario del centro. Recuerda el párrafo de Castañeda sobre la situación de la década de 1820 citado antes. Véase si no:

Este proceso se facilitó como resultado de la crisis de 1995, cuando los estados ejercieron presión sobre la federación, a cambio de su 
adhesión al incremento del IVA de ese año. A su vez, esto ocasionó una mayor participación política de los partidos de oposición, en particular del Partido Acción Nacional, que fue ganando terreno. Se puede decir que a partir de 1997, con el primer Congreso dividido, y hasta la fecha, no ha habido proyecto de presupuesto federal presentado por el Ejecutivo federal que no haya sido aprobado con alguna concesión a estados y municipios en materia de gasto. Incluso se creó un nuevo ramo presupuestario, el Programa de Apoyo Financiero a Entidades Federativas (PAFEF), que se ha incrementado año con año y que constituye de facto una adición a las participaciones federales. Asimismo, los estados reciben una parte de los excedentes petroleros. ${ }^{31}$

\section{Otro estudioso se refiere al mismo cambio:}

Desde antes, pero sobre todo durante los años en que el Partido Acción Nacional (PAN) gobernó (diciembre de 2000 a noviembre de 2012), los gobernadores de los estados y el Jefe de Gobierno del Distrito Federal vieron crecer su poder y multiplicar su participación en el gasto público federal. A las tradicionales participaciones en los impuestos federales (que por Ley de Coordinación Fiscal les corresponde desde 1980), se vinieron a sumar, a partir de 1992, diversos fondos de apoyo con los cuales pudieron multiplicar su influencia en el rumbo de la nación. ${ }^{32}$

En esa perspectiva, la llamada transición democrática aparece como un factor demoledor del federalismo fiscal posrevolucionario. Pero como ha intentado mostrarse, la demolición no comenzó con esa transición. Cabe insistir en la cronología, en particular en el cambio drástico ocurrido a partir de la negociación de 1972-1973. ¿No será que ya desde esos años se vivía un rápido deterioro del centro político y un ascenso de los intereses provincianos? Da la impresión de que la fama del llamado

31 Hernández Trillo, “Las finanzas”, p. 597.

32 Tello, La economía política, p. 382. 
populismo, junto con el petróleo, ha obnubilado nuestra mirada sobre la década de 1970.

En otro plano, cabe preguntarse: ¿qué grupos económicos empujaron la transformación del federalismo fiscal mexicano?, ¿qué papel jugaron los empresarios provincianos en ese cambio y cómo se relacionaban con el Partido Acción Nacional, cuyo papel parece decisivo, según se desprende de los párrafos de Hernández Trillo y Tello citados antes? Piénsese al menos en los industriales y banqueros neoleoneses y en los agricultores y comerciantes del noroeste. ¿Era el panismo la vía de expresión de los intereses provincianos? ¿Acaso tal era una de sus fortalezas? Recuérdese que, durante la década de 1920, si no es que desde antes, grandes empresas mexicanas y extranjeras apoyaron al gobierno federal en su esfuerzo por imponerse a los gobiernos estatales, al menos en materia de aguas y de petróleo. ¿Se puede hablar de un fenómeno equivalente después de 1972, pero en sentido contrario? Ojalá la nueva generación de historiadores aclare el asunto.

Otro aspecto importante que subyace a las cifras del cuadro 2 se refiere al efecto pernicioso de la elevada disponibilidad de recursos federales en las entidades federativas. La creciente disponibilidad de recursos federales en los estados (y municipios) guarda estrecha relación con el problema tributario general del país, a saber, la baja carga fiscal, rasgo que desde hace unos 80 años viene dando lamentable fama a México en todo el orbe. ${ }^{33}$ Esa baja carga fiscal tiene una de sus partes más complejas en esta dimensión federalista, en particular en la escasa recaudación del impuesto predial, el impuesto local por antonomasia. Un estudio reciente pone al día la discusión sobre este tema fundamental, a saber, la relación entre el ascenso de las participacio-

${ }^{33}$ Una estimación del Banco Mundial indicaba que en 1995 y 1998 la carga tributaria de México rondaba $14.8 \%$ del PIB, monto que contrastaba no tanto con Croacia (43\%) sino con Uruguay (29\%), Panamá (19\%) y Chile (18\%). Véase Elizondo, Impuestos, p. 9. 
nes y aportaciones federales y la trayectoria de la recaudación de las haciendas locales, en particular la baja recaudación que hacen las haciendas municipales del impuesto predial. ${ }^{34}$ ¿Acaso el gobierno federal también tendrá que hacerse cargo de ese impuesto, como lo sugirió Romero en 1870 y como lo intentó hacer el secretario Adolfo de la Huerta en $1923 ?^{35}$ Y más allá: ¿acaso el hilo de la madeja tiene que ver a final de cuentas con el poderío de las coaliciones locales tejidas entre gobiernos y propietarios que se han opuesto invariablemente, como ocurría en Estados Unidos a fines del siglo xIx, a una mayor cobranza del impuesto a la propiedad? ¿Acaso se recurrió a la soberanía estatal para defender los intereses de esa coalición? ¿ Tiene razón el profesor Carmagnani cuando afirma que el "estamento propietario" hizo todo lo posible por frenar, entre 1820 y la década de 1880, el esfuerzo del gobierno federal por hacerse de una verdadera autonomía financiera y de una soberanía territorial?36 Y si este historiador tiene razón, ¿̇cómo se manifiesta esa postura de la clase propietaria a fines del siglo xx? Sea lo que sea, es lamentable que no contemos en México con investigaciones sistemáticas sobre los impuestos territoriales y por supuesto acerca de su relación con el fraude fiscal. En España sí se ha estudiado. ${ }^{37}$

\section{CONCLUSIONES}

La extinción de la CF en 1948 es un acontecimiento de gran simbolismo que ilumina las distintas etapas que ha recorrido la relación centro-provincias en México. De entrada, ayuda a aclarar el contraste notable entre dos épocas, que de manera burda corresponden a los siglos xix y xx. La primera es la época del ascenso provinciano y del debilitamiento federal, que explica

${ }^{34}$ Unda y Moreno, "La recaudación".

${ }^{35}$ Véase Secretaría de Hacienda, Convención Nacional Catastral.

36 Carmagnani, "Finanzas", p. 166.

${ }^{37}$ Véase Pro Ruiz, "El poder de la tierra”. 
la creación del contingente, de la CF; y la segunda, caracterizada por el ascenso federal y la postración provinciana, que explica la extinción de la CF. El acontecimiento de 1948 también ayuda a aclarar la deuda que tenía el gobierno del presidente M. Alemán con el esfuerzo iniciado en la década de 1870 para fortalecer las finanzas federales. La expansión de la soberanía tributaria federal al conjunto de la población y del territorio es un hecho clave que no se vio interrumpido por la revolución de $1910 \mathrm{ni}$ por los gobiernos posrevolucionarios. Al contrario, la creación del ISR en 1925, junto con la "federalización" (entendida como se entendía en esos años, es decir, como expansión federal) de varios ramos tributarios en los años 1920-1950, apuntan en la misma dirección. Además, la potencia recaudadora del IsR, por ser un impuesto personal, directo y teóricamente progresivo, explica en buena medida la posibilidad de la hacienda federal de "sacrificarse" al dar paso a la extinción de 1948. Era el momento culminante del poderío federal.

Como se vio, la extinción de la CF también ayuda a aclarar los acontecimientos posteriores a 1948. En particular, destaca el arreglo de 1972-1973, que a nuestro juicio marca el final del auge federal, así como el inicio de una nueva época de ascenso de las provincias, como si se repitieran los vaivenes o ciclos que un destacado historiador ha propuesto para la historia del federalismo brasileño. ${ }^{38}$ En México desde 1973 puede apreciarse el aumento sostenido del monto de ingresos federales destinados a los gobiernos provincianos. Así que un resultado concreto de este recorrido en torno a la extinción de la CF es considerar el periodo 1948-1972 como la cúspide del poderío federal en el terreno hacendario (y cabe preguntarse si no ocurre lo mismo en otros rubros). En términos de una periodización larga, la distinción y caracterización fina de tal periodo es imperativo.

${ }^{38}$ Carvahlo, "Federalismo y centralización”. 
Pero se trata de un poderío muy breve y además frágil. Recuérdese la fuerte oposición de 14 entidades federativas a sumarse al IsIM, una cuestión cuyo estudio a profundidad promete sorpresas en torno al presunto poderío presidencial frente al poder disperso pero consistente de algunas entidades federativas. Del mismo modo, se propuso que en el arreglo de 1972-1973 reside el origen del declive federal, apuntalado luego por la coordinación fiscal resultante del IVA y más tarde por la movilización electoral que dio paso a la transición democrática. Por lo visto, después de 1980 los dineros federales (renta petrolera) sirvieron para llegar a un nuevo entendimiento con los intereses provincianos, al parecer bien representados por el PAN. Este arreglo dibuja la situación contemporánea, cuyos rasgos (estancamiento económico, salarios deprimidos, caída petrolera, inseguridad galopante, desilusión en torno a la democracia) hacen recordar la aseveración del presidente Cárdenas referida a la inyección de vitalidad a los gobiernos estatales como fuente de tragedias nacionales. ¿Acaso será necesario empezar a pensar en reinstaurar el contingente o la contribución federal? Así parece sugerirlo el actual secretario de Hacienda, según se lee en el epígrafe. ¿Pero cómo pensar en ello si los estados desde hace años virtualmente se olvidaron de su soberanía tributaria en lo que se refiere a la recaudación? Para los gobiernos estatales (y municipales) resulta más cómodo seguir exigiendo y recibiendo fondos federales que esmerarse en la ingrata tarea de recaudar impuestos. Además, es bien sabido, el manejo que hacen las provincias de los fondos federales dista de ser pulcro y transparente.

En suma, a partir de la extinción de la CF en 1948 este trabajo ha intentado mostrar la pertinencia de elaborar una perspectiva de largo plazo en torno a una historia que hace énfasis en la relación centro-provincias y en la formación del centro político. Para ello, propone dedicar la atención a varios acontecimientos fundamentales pensando en armar una periodización novedosa: a) el arreglo tributario de 1824, que crea el contingente; $b$ ) el 
nacimiento del impuesto del timbre en 1870-1876 y del ISR en 1924-1925); c) la extinción de la CF y el auge federal 1948-1972, y d) el arreglo de 1972-1973 como inicio de un nuevo ascenso provinciano. Siguiendo en cierto modo a Lucas Alamán y a Lázaro Cárdenas, la hipótesis general es que el centro político jamás pudo imponer su poderío sobre las provincias y que en éstas la coalición de los gobernantes con las clases propietarias ha sido a final de cuentas la que ha impuesto el devenir de la historia general. Prueba de ello es una singularidad tributaria mexicana que nos da fama en el mundo: la baja carga fiscal, un asunto no tratado aquí pero que es el trasfondo de la historia política expuesta en estas líneas. Por tal razón merece investigaciones concienzudas.

\section{REFERENCIAS}

Aвoites Aguilar, Luis, “Alcabalas posporfirianas. Modernización y soberanía estatal”, en Historia Mexicana, LI: 2 (202) (oct.-dic. 2001), pp. 363-393.

Aвоites Aguilar, Luis, Excepciones y privilegios. Modernización tributaria y centralización política en México, 1922-1972, México, El Colegio de México, 2003.

Авоites Aguilar, Luis, La disputa mexicana por el petróleo. Veracruz versus la nación (1922-1935), México, Archivo Histórico de la Suprema Corte de Justicia de la Nación, 2011.

Авoites Aguilar, Luis y Luis Jáuregui (coords.), Penuria sin fin. Historia de los impuestos en México, siglos XVIII-XX, México, Instituto de Investigaciones Dr. José María Luis Mora, 2005.

Alamán, Lucas, Historia de México desde los primeros movimientos que prepararon su independencia en el año de 1808 hasta la época presente, México, Instituto Cultural Helénico, Fondo de Cultura Económica, 1988, 5 volúmenes.

Beteta, Ramón, Tres años de política hacendaria, México, Secretaría de Hacienda y Crédito Público, 1951.

Brownlee, W. Elliot, Federal Taxation in America. A Short History, Washington, Woodrow Wilson Center, 1996. 
Carmagnani, Marcello, Estado y mercado. La economía pública del liberalismo mexicano, 1850-1911, México, El Colegio de México, Fondo de Cultura Económica, Fideicomiso Historia de las Américas, 1994.

Carmagnani, Marcello, "Finanzas y Estado en México, 1820-1880", en Jáuregut y SERrano (coords.), 1998, pp. 131-177.

Carmagnani, Marcello (coord.), Federalismos latinoamericanos: México/Brasil/Argentina, México, Fondo de Cultura Económica, El Colegio de México, Fideicomiso Historia de las Américas, 1996.

Carvalho, José Murilo de, "Federalismo y centralización en el imperio brasileño: historia y argumento”, en CARMAGNANI (coord.), 1996, pp. 51-80.

CASTAÑEda ZaVALA, Jorge, "El contingente fiscal en la nueva nación mexicana, 1824-1861”, en Marichal y Marino (comps.), 2001, pp. 135-188.

Comín, Francisco y Juan Zafra OteYZa (eds.), El fraude fiscal en la bistoria de España, Madrid, Instituto de Estudios Fiscales, Ministerio de Economía y Hacienda, 1994.

Chapoy Bonifaz, Dolores B. et al., El federalismo en sus aspectos educativos y financieros, México, Universidad Nacional Autónoma de México, 1976.

Estadísticas históricas de México 2014, Aguascalientes, Instituto Nacional de Estadística y Geografía (version digital).

Elizondo, Carlos, Impuestos, democracia y transparencia, México, Auditoría Superior de la Federación, 2001.

FARÍAs, Urbano, “Aspectos financieros del estado federal mexicano", en CHAPOY BONIFAZ et al., 1976, pp. 67-103.

Gómez Tagle, Gustavo, "La contribución federal”, en Revista de Hacienda (jun. 1939), pp. 15-34.

Hernández Trillo, Fausto, "Las finanzas públicas en el México posrevolucionario”, en KunTz (coord.), 2015, pp. 573-602.

INEGI, Finanzas públicas estatales y municipales 1970-1982, México, 1984.

INEGI, Finanzas públicas estatales y municipales 1976-1985, México, 1988. 
INEGI-BIE, Banco de Información Económica. Finanzas públicas estatales 19892015. Ingresos y egresos brutos estatales por entidad federativa.

INEGI-BETA, Registros administrativos. Finanzas públicas estatales y municipales. Tabulados. Finanzas públicas municipales 1989-2015.

Informe Nuevo León 1974, Primer informe de gobierno de Pedro Zorrilla Martinez, gobernador de Nuevo León. 1 de marzo de 1974, Monterrey, s.e., 1974.

Informe Sonora 1975, Primer informe de gobierno. Lic. Carlos Armando Biebrich Torres. Sonora. Septiembre 73-Enero 75, Hermosillo, Gobierno del estado, enero de 1975.

Jannetti Díaz, María Emilia, "La coordinación fiscal y los ingresos estatales", en Comercio Exterior, 39: 9 (sep. 1989), pp. 769-774.

Jáuregui, Luis, "Los orígenes de un malestar crónico. Los ingresos y los gastos públicos en México, 1821-1855”, en Aboites Aguilar y Jáuregui (coords.), 2005, pp. 79-114.

Jáuregui, Luis y José Antonio Serrano (coords.), Las finanzas públicas en los siglos XVIII y XIX, México, Instituto de Investigaciones Dr. José María Luis Mora, El Colegio de Michoacán, El Colegio de México, 1998.

Kuntz, Sandra (coord.), Historia económica general de México. De la Colonia a nuestros días, México, El Colegio de México, Secretaría de Economía, 2015.

Marichal, Carlos y Daniela Marino (comps.), De colonia a nación. Impuestos y política en México, 1750-1860, México, El Colegio de México, 2001.

México: Las finanzas nacionales, el presupuesto y la crisis económica mundial, México, Cámara de Diputados, XLIX Legislatura, 1974.

Molina Armenta, María del Ángel, "La coordinación del sistema tributario del comercio y la industria en México: el Impuesto sobre Ingresos Mercantiles (ISIM), 1947-1980", tesis de doctorado en historia, México, Instituto de Investigaciones Dr. José María Luis Mora, 2016.

Palavicini, Félix F., Historia de la Constitución de 1917, México, Universidad Nacional Autónoma de México, Instituto Nacional de Estudios Históricos de las Revoluciones de México, 2014, 2 vols. (edición facsimilar). 
Petricioli, Gustavo, "Sobre los efectos económicos de las nuevas disposiciones fiscales”, en El Economista Mexicano, Ix: 2 (feb.-mar. 1973), suplemento, pp. 55-62.

Pro Ruiz, Juan, "El poder de la tierra: una lectura social del fraude en la contribución de inmuebles, cultivo y ganadería en España (1845-1936)", en Comín y Zafra Oteyza (eds.), 1994, pp. 189-201.

Secretaría de Hacienda y Crédito Público, Convención nacional catastral, México, Cultura, 1924.

Secretaría de Hacienda y Crédito Público, Primera convención nacional fiscal. Memoria, México, Cultura, 1926.

Secretaría de Hacienda y Crédito Público, Segunda convención nacional fiscal. Memoria, México, 1933, 3 volúmenes.

Secretaría de Hacienda y CRÉdito PÚblico, Tercera convención nacional fiscal. Memoria, México, 1947, 3 volúmenes.

Secretaría de Hacienda y Crédito Público, Seis años de política hacendaria, 1970-1976, México, 1976.

SERvín G., Armando, Las finanzas públicas locales durante los últimos cincuenta años, México, Secretaría de Hacienda y Crédito Público, 1956.

Sobrino, Luis Jaime, Migración interna en México durante el siglo Xx, México, Consejo Nacional de Población, 2010.

Tello Macías, Carlos, La economía política de las finanzas públicas: México 1917-2014, México, Universidad Nacional Autónoma de México, 2014.

TRevisán, Egidio, Reforma del régimen rentístico argentino, Buenos Aires, Jacobo Peuser, 1932.

Uнтноғ, Luz María, "La difícil concurrencia fiscal y la contribución federal, 1861-1924. Notas preliminares”, en Historia Mexicana, LIv: 1 (213) (jul.-sep. 2004), pp. 129-178.

Unda, Mónica y Carlos Moreno Jaimes, "La recaudación del impuesto predial: un análisis de sus determinantes económicos en el periodo 1969-2010", en Revista Mexicana de Ciencias Políticas y Sociales, Lx: 225 (sep.-dic. 2015), pp. 53-84. 
VÁzquez, Josefina Zoraida, “El federalismo mexicano, 1823-1847”, en CARMAGNANI (coord.), 1996, pp. 15-50.

YÁñez Ruiz, Manuel, El problema fiscal en las distintas etapas de nuestra organización política, México, Secretaría de Hacienda y Crédito Público, 1959, 6 volúmenes. 